\title{
Arteriovenous Fistula: A Rare Complication of Peripheral Venous Cannulation and an Example of the Importance of Clinical Examination
}

\section{Williams $\mathrm{AE}^{1 *}$ and Sinha $\mathrm{P}^{2}$}

${ }^{1}$ Leeds Institute of Biological and Clinical Sciences, Level 7 Clinical Sciences Building, St James's University Hospital, Leeds, LS9 7TF, UK ${ }^{2}$ Department of General Surgery, Princess Royal University Hospital, Farnborough Common, Orpington, Kent, BR, UK

\begin{abstract}
Arteriovenous fistula is a rare complication of peripheral venous cannulation. We report a case of a 79-yearold male who presented with a subcutaneous swelling on the anterio-lateral aspect of his right forearm. The 'lump' developed at the same site as the insertion of a previous peripheral venous cannula. Careful clinical examination and later radiological confirmation diagnosed an arteriovenous fistula. The patient was referred to a vascular surgeon for advice regarding further management. This case demonstrates the importance of clinical examination for the accurate diagnosis of 'Lumps and Bumps' prior to surgical treatment.
\end{abstract}

Keywords: Arteriovenous fistula; Traumatic; Complications; Peripheral venous cannulation

\section{Introduction}

Arteriovenous Fistula (AVF) is defined as an anomalous communication between an artery and a vein [1]. Acquired AVFs are a rare clinical finding compared to the congenital type. They are most commonly secondary to penetrating and blunt trauma, iatrogenic complications of invasive procedures and operations, infection, aneurysm and blood vessel inflammation [2]. Although still rare iatrogenic AVFs are more commonly reported now due to the increased use of percutaneous diagnostic and interventional endovascular procedures $[3,4]$. Such procedures require catheterisation of the large arteries and thus most reported cases of AVFs secondary to such percutaneous needle puncture techniques involve the femoral vessels [4]. The reported rate of AVF varies from $0.006 \%$ to $0.14 \%$ [5]. We present a rare case of a 79-year-old man who developed an AVF after peripheral venous cannulation that was required for intravenous access during an inpatient hospital stay 5 months earlier.

\section{Case Report}

A 79-year-old gentleman was referred from general practice to the local general surgical clinic due to a bothersome 'lump' on his right forearm. The lump had developed over a period of 5 months and was becoming tender to touch. On clinical examination a soft, pulsatile, approximately $1 \mathrm{~cm} \times 1 \mathrm{~cm}$ mass was noted on the anterior-lateral aspect of his right forearm (Figure 1). An audible bruit was present in the mass. On closer questioning the patient volunteered he recalled having an intravenous cannula inserted in that area of his arm while previously an in-patient stay when he required intravenous antibiotic treatment for an episode of acute diverticulitis.

A diagnosis of AVF secondary to traumatic vessel puncture was made clinically and he was referred to the local vascular service. The patient underwent duplex ultrasound scanning of the mass that confirmed the diagnosis. The scan demonstrated a localised dilatation of the affected vein, which contained an arterial signal. A branch of the radial artery was visualised passing behind the vein to form the abnormal communication (Figures 2 and 3 ).

The patient was reviewed in clinic with the results of the duplex ultrasound and opted for a conservative treatment strategy as over time the 'lump' was less bothersome and agreed to repeat review if there was any change in size or symptoms.

\section{Discussion}

AVFs were first described clinically in 1757 by William Hunter [6]. Presentation and symptoms of acquired AVFs are dependent on the cause, location and extent of vessel involvement [2]. Those due to penetrating trauma such as stabbings and gunshot wounds that cause frank haemorrhage are obvious emergencies and present soon after initial injury [7]. However AVF presentation and subsequent treatment can be delayed for many months or years [8]. Common findings on clinical examination are a history of trauma to the area concerned, pain, oedema, disfigurement and symptoms of arterial insufficiency [2]. If longstanding an AVF in the lower limb, for example, can give rise to symptoms similar to that of chronic venous insufficiency and thus delay diagnosis [8].

Careful examination is required in order to detect the pathognomonic machinery murmur, or bruit, and thrill over the site

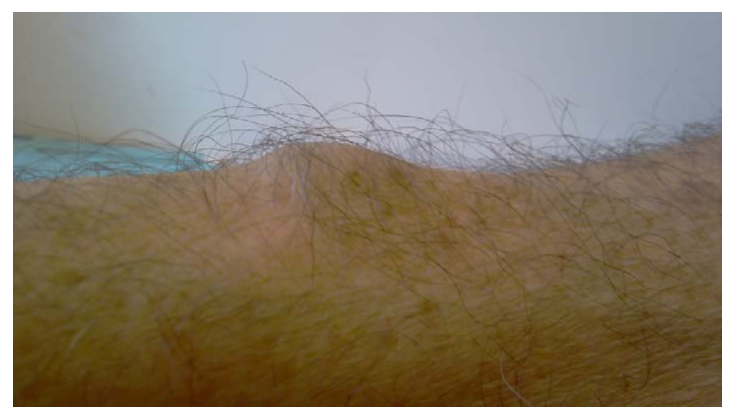

Figure 1: Subcutaneous swelling found at previous peripheral venous cannulation site found to be an arteriovenous fistula.

*Corresponding author: Williams AE, Clinical Research Fellow, Leeds Institute of Biological and Clinical Sciences, Level 7 Clinical Sciences Building, St James's University Hospital, Leeds, LS9 7TF, UK, Tel: 440113 2065281; E-mail: a.e.williams@leeds.ac.uk

Received January 27, 2016; Accepted March 03, 2016; Published March 13 2016

Citation: Williams AE, Sinha P (2016) Arteriovenous Fistula: A Rare Complication of Peripheral Venous Cannulation and an Example of the Importance of Clinical Examination. Med Rep Case Stud 1: 105. doi: 10.4172/2572-5130.1000105

Copyright: () 2016 Williams AE, et al. This is an open-access article distributed under the terms of the Creative Commons Attribution License, which permits unrestricted use, distribution, and reproduction in any medium, provided the original author and source are credited. 
Citation: Williams AE, Sinha P (2016) Arteriovenous Fistula: A Rare Complication of Peripheral Venous Cannulation and an Example of the Importance of Clinical Examination. Med Rep Case Stud 1: 105. doi: 10.4172/2572-5130.1000105

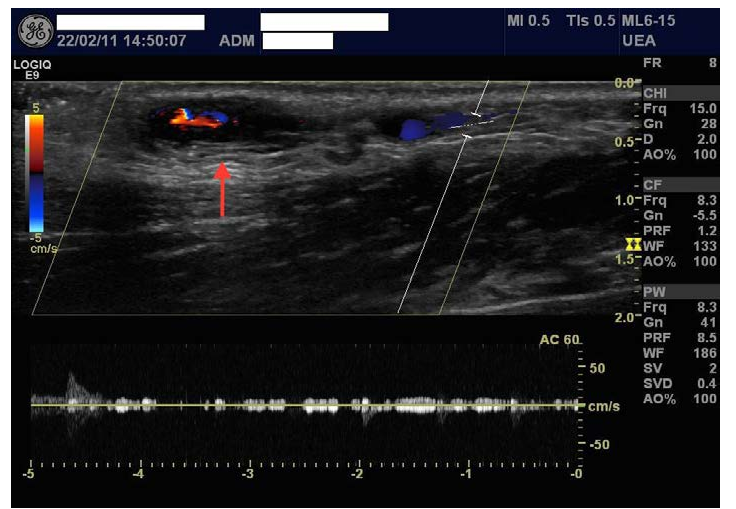

Figure 2: High frequency linear longitudinal ultra-sound image of the forearm soft tissue mass demonstrating localised dilatation of a patent vein with a mixed venous-arterial waveform.

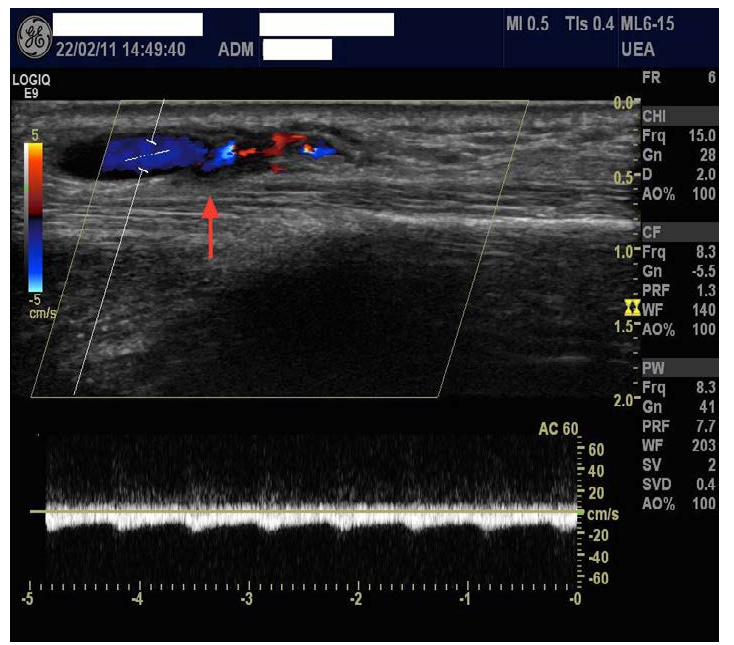

Figure 3: High frequency linear longitudinal ultra-sound image of the forearm soft tissue mass demonstrating localised dilatation of a patent vein with a mixed venous-arterial waveform.

of previous injury [9]. Thus diagnosis is usually a clinical one; however radiological confirmation is useful for treatment planning. Digital subtraction arteriography is the gold standard for diagnosing AVFs, but duplex ultrasound scanning and magnetic resonance imaging are less invasive and allow for quicker confirmation [9].

Iatrogenic AVF formation secondary to peripheral intravenous cannulation is rare [5]. More reports exist in the literature of AVFs forming in the regions of the groin and neck. The close anatomical relationship of the great vessels in these regions means accidental puncture of either vein or artery can occur during vessel access procedures. The reported incidence of AVF formation secondary to peripheral cannulation is less than $0.003 \%$ and only 2 other cases have reported distal upper-limb vessel involvement-one in a hand due to cannulation and another due to peripheral blood venepuncture [10]. This rare case of an AVF in an upper limb after routine peripheral cannulation follows the typical insidious time gap, of months rather than weeks, between original injury and the development of a symptomatic AVF.

The decision to treat AVFs depends on the cause, size, location and haemodynamic effect that the fistula is having on the patient [11].
Serious complications of large AVFs if untreated include proximal vessel dilatation, pseudoaneurysm formation, fistula rupture and haemorrhage, neuropathy and thromboemboilic events. Longstanding effects of AVFs can lead to cardiac overload and subsequent failure, which may not be completely reversible once the fistula is closed [9]. It is feasible to leave small asymptomatic lesions and manage them conservatively with regular follow up in clinic [2]. For traumatic AVFs of the upper limb the most successful treatment is surgical ligation, with or without reconstruction depending on the arterial perfusion [2]. Early treatment is recommended as potential complications such as scaring and distorted anatomy are reduced [7,9]. In this case endovascular coiling could also be used to close the fistula, as the lesion was not involving an end artery thus there is no risk of distal ischaemia and subsequent necrosis.

\section{Conclusion}

This case highlights the importance of careful clinical examination. Simple 'lumps and bumps' are a common referral to any general surgical clinic, and may end up on an inexperienced and junior surgeon's local anaesthetic operating list. Without careful and thorough history taking and examination the intraoperative complications for this patient may have been severe. It also serves as a cautious reminder that everything we do to patients has potential complications associated with it. Although a rare complication, the simple procedure of placing an intravenous cannula led to this patient requiring additional surgical management.

\section{Acknowledgement} report.

We thank the patient for their consent for allowing the production of this case

\section{Competing Interests}

No financial or commercial conflicts of interest to declare for either author.

\section{References}

1. Straton CS, Tisnado J (2000) Spontaneous arteriovenous fistulas of the lower extremities : angiographic demonstration in five patients with peripheral vascular disease. Case Reports 23: 318-321.

2. Ha JF, Hons M, Sieunarine K (2009) Arteriovenous fistula secondary to recurrent metacarpophalangeal joint dislocation : A Case Report. Oschsner J 9: 14-16.

3. Tayama K, Akashi H, Hiromatsu S, Okazaki T, Yokokura Y, et al. (2005) Acquired arteriovenous fistula of the right forearm caused by repeated blunt trauma: a report of a rare case. Ann Thorac Cardiovasc Surg 11: 59-62.

4. Cil BE, Akmangit I, Peynircioğlu B, Karçaaltincaba M, Cekirge S (2006) latrogenic femoral arteriovenous fistula: endovascular treatment with covered stent implantation and 4-year follow-up. Diagn Interv Radiol 12: 50-52.

5. Kelm M, Perings SM, Jax T, Lauer T, Schoebel FC, et al. (2002) Incidence and clinical outcome of iatrogenic femoral arteriovenous fistulas implications for risk stratification and treatment. J Am Coll Cardiol 40: 291-297.

6. May JJ, Atkinson R, Rosen H (1984) Traumatic arteriovenous fistula of the thumb after blunt trauma: a case report. J Hand Surgery 9: 253-255.

7. Robbs J, Carrim A, Kadwa A, Mars M (1994) Traumatic arteriovenous fistula: Experience with 202 patients. Br J Surg 81: 1296-1299.

8. Huang W, Villavicencio JL, Rich NM (2005) Delayed treatment and late complications of a traumatic arteriovenous fistula. J Vasc Surg 41: 715-717.

9. Nagpal K, Ahmed K, Cuschieri R (2008) Diagnosis and management of acute traumatic arteriovenous fistula. Int J Angiol 17: 214-216.

10. Shararah AWH, Aldekhayel S, Williams HB (2012) latrogenic arteriovenous fistula in the hand: A case report. J Plast Reconstr Aesthetic Surg 65: e351-353.

11. Creech O, Gantt J, Wren H (1965) Traumatic arteriovenous fistula at unusual sites. Ann Surg 161: 908-920. 